\section{Frequency of houselight interruption as a dimension for inhibitory generalization testing}

\author{
R. A. BOAKES* \\ University of Sussex, Brighton, England
}

Pigeons were trained under free operant successive-discrimination conditions in which the discriminative stimuli were initially steady and pulsed noise and subsequently were steady houselight, positive stimulus, and flashing houselight, negative stimulus. Discrimination was poor under the first set of conditions but developed rapidly with the second set of stimuli. On reaching criterion in the discrimination involving the flashing houselight, a generalization test was given in which a number of different frequencies of houselight interruption were presented, both at full and reduced amplitude. The regularity of the negative gradients obtained indicated that this provided a suitable dimension for the study of inhibitory generalization.

Negative generalization gradients have recently been widely studied (Hearst et al, 1970), using what has become a standard procedure. Following training to respond to $S_{1}$, the positive stimulus, and to withhold responses to $S_{2}$, the negative stimulus, Ss are given generalization tests in which the stimuli are values along a dimension containing $\mathrm{S}_{2}$ and, it is generally assumed, orthogonal to $\mathrm{S}_{1}$. Apparently without exception, subsequent research has used the two stimulus dimensions employed in the pioneer studies (Jenkins \& Harrison, 1962 ; Honig et al, 1963 ; Schwartzbaum \& Kellicut, 1962), namely, the orientation of a line projected on the response key or the frequency of a pure tone.

Certain problems are associated with the use of each of these dimensions. For line orientation, the major ones are: (1) since response rates are low during the test, Ss may spend a considerable amount of time oriented away from the response key and thus not perceive the stimuli, and (2) presenting the stimuli involves either a sophisticated slide projection system or an in-line display unit which, though simple, is less flexible and allows the possibility of artifactual effects (Gardner \& Ely, 1969). Though many gradients using this dimension have been published, personal communications to the author suggest that there have been many unaccountable failures to obtain regular functions with this dimension. Although the use of tonal frequency avoids the above problems, it

* This research was supported in part by the U.K. Science Research Council. The author is very grate ful for the able assistance of Jennifer Calduell-Smith and Bundy Wilson. introduces new ones: (1) acquisition by pigeons of discriminations involving tones is typically very much slower than those involving localized visual stimuli; and (2) to ensure that the loudness of the test stimuli is constant requires psychophysical data on equal loudness contours that are not available for the pigeon.

The following experiment was intended to explore the potential of two alternative dimensions for the study of inhibitory generalization. It was hoped that at least one would avoid the disadvantages of using localized visual stimuli, but at the same time lead to rapid acquisition.
The first situation involved a discrimination between steady and interrupted noise. When acquisition was found to be slow in this situation, a discrimination between steady and interrupted houselight was introduced. METHOD

The Ss were six homing pigeons with prior experience limited to autoshaping, variable-interval schedule training, and extinction of pecking a white response key. The apparatus consisted of a standard pigeon chamber with a single response key mounted centrally over the grain-hopper aperture. An incandescent white bulb mounted on the ceiling at the rear of the chamber served as houselight. The key could be illuminated by a green light, and a ceiling-mounted speaker could provide white noise at approximately $80 \mathrm{~dB}$ re $.0002 \mathrm{dynes} / \mathrm{cm}^{2}$ intensity. Reinforcement consisted of $3 \mathrm{sec}$ access to the grain hopper. The chamber was enclosed within a soundproofed cubicle.

Training began with a CRF reinforcement schedule which was gradually changed to VI 30 sec over the first two sessions. The keylight and houselight were on during 60 sec periods, which were separated by 5 -sec blackouts. Each session contained 40 periods. These parameter values were maintained until the final generalization test. White noise was maintained steadily throughout a session.

After the initial two sessions,

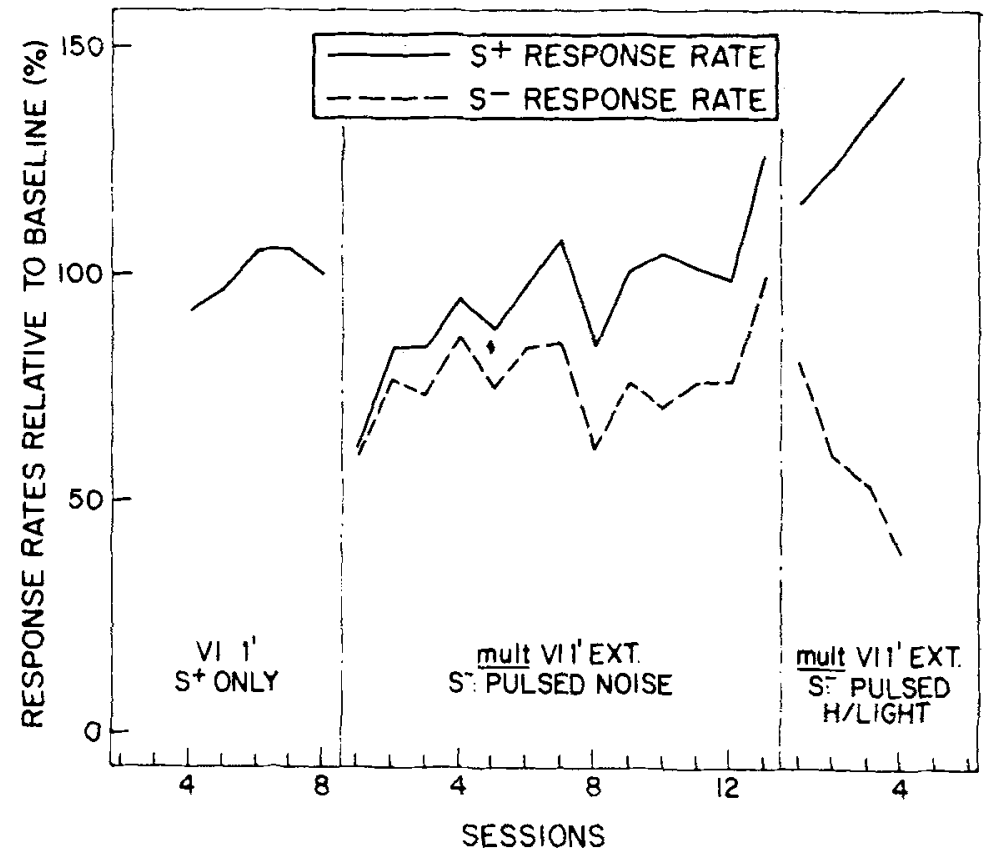

Fig. 1. Response rates as a percentage of baseline rates averaged over Ss. These are shown for Baseline Sessions 4-8, the 13 sessions of the first discrimination, and Sessions 1-4 of the second discrimination. 


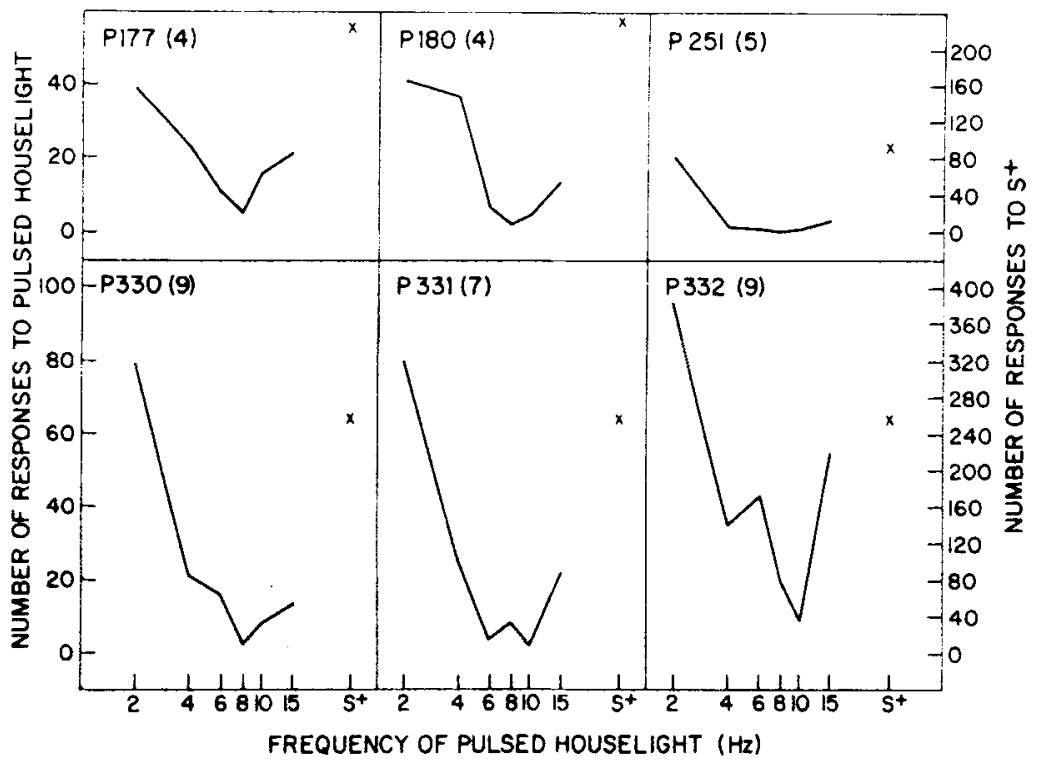

Fig. 2. Number of responses to the high-amplitude stimuli (left-hand scale) and to S+ (indicated by " $X$ " to scale on right-hand side) during the generalization test. The number of sessions to criterion for a given $S$ is given by the figure in parentheses after the $S$ number.

baseline training was given for eight sessions on a VI 1-min schedule. Subsequently, discrimination training was begun such that the keylight, the houselight, and the white noise were maintained at constant intensity during the 20 positive periods in each session, and during these periods, reinforcement continued to be available on the VI 1-min schedule. Negative periods, in which no reinforcement was available, were distinguished by periodic interruption of the noise at $8 \mathrm{~Hz}$, with the noise at full intensity for half a cycle and off for the remainder of a cycle. Positive and negative periods occurred in randomized order, with the constraint that each could occur no more than three times in succession.

The first discrimination conditions were maintained for 13 sessions and on the following session, conditions during negative periods were changed so that now the houselight was periodically interrupted at $6 \mathrm{~Hz}$ with equal on and off times, while the noise source was maintained at a constant intensity. Conditions during positive periods remained as before. This second discrimination situation was continued for each $S$ until its discrimination ratio, the ratio of negative to positive response rates, had reached a criterion value of $10 \%$ within a session.

In the session following the criterion session, a generalization test was given in which stimuli were presented for periods of $30 \mathrm{sec}$ with an interstimulus blackout of $5 \mathrm{sec}$. This test session contained an initial warm-up phase of 6 periods in which the $\mathrm{S}^{+}$, steady houselight, was presented and reinforcement was available on the VI 1-min schedule. Reinforcement was withheld for the remainder of the session in which six blocks of 14 stimulus periods occurred. Each block contained $2 \mathrm{~S}+$ periods and 1 period of each of the following stimuli: high-amplitude pulsing of the houselight at $2,4,6,8$, 10 , and $15 \mathrm{~Hz}$, where, as in previous negative components, the light was switched from full intensity $(2.2 \mathrm{~W})$ to zero intensity; low-amplitude pulsing at these same frequencies, where the light was switched from full intensity to a moderate intensity $(1.3 \mathrm{~W})$. The on and off times were equal at all frequencies. The stimuli were randomized within a block, and each $S$ received a different sequence. At both amplitudes, a distinct flicker was perceived by human Os at all frequencies.

In Fig. 1, the average relative response rates for the six Ss are shown for the final five baseline sessions, the first discrimination, and the first four sessions of the second discrimination. For this discrimination, only four sessions are included because two Ss reached criterion on the fourth session. The averages shown in the figure were obtained after the rates in each session for individual Ss had been expressed as a percentage of the median rate over the final five baseline sessions. The functions in Fig. 1 are characteristic of the data for individual Ss. Although the introduction of negative components with the pulsed noise in the first discrimination led to an initial sharp drop in response rates, subsequent acquisition of the discrimination was slow. Over the final two sessions, the average discrimination ratio was 0.43 , the range being $0.35-0.49$.

With the introduction of the pulsed houselight as the negative stimulus, the development of differential response rates became rapid. By the fourth session, the discrimination ratio for each $S$ was lower than that of any session in the first discrimination. The number of sessions to the criterion of a $10 \%$ ratio ranged from four to nine. This number is given in parentheses after the $S$ number in Fig. 2, which shows the responses made by each $S$ to the high-amplitude stimuli in the generalization test.

All Ss responded regularly throughout the test session, and the rate of responding was a regular function of pulse frequency for the high amplitude stimuli. These functions are plotted on a log frequency scale in Fig. 2, as this provided more symmetry than an arithmetic scale. It can be seen that each $\mathrm{S}$ generated an inverted- $U$ function, but with the minimum to the high-frequency side of the S- value, $6 \mathrm{~Hz}$. The number of responses to the steady houselight, $\mathrm{S}+$, which was presented twice as often as any pulsed stimulus, is shown on the right of each graph to the scale indicated on the right-hand side of the figure.

Response rates were much greater to the low-amplitude than to the high-amplitude stimuli, but were more variable. However, the average function was of the same form as that for high-amplitude stimuli, as is shown in Fig. 3. For each $S$, response rates to the pulsed stimuli were expressed as a

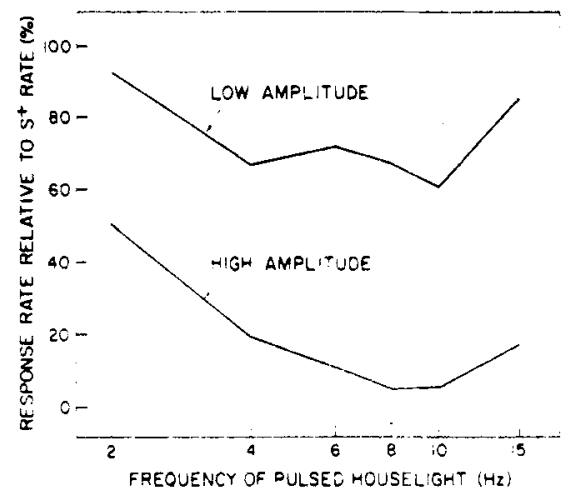

Fig. 3. Mean response rates to both high- and low-amplitude stimuli as a function of pulse frequency. Response rates are expressed as a percentage of rates to $S+$ during the generalization test. 
percentage of rates to $\mathrm{S}+$ during the test, and the means of these percentages are plotted in Fig. 3.

\section{DISCUSSION}

The slow acquisition obtained when the negative stimulus was pulsed noise suggests that this is not a convenient stimulus for investigating stimulus control. In contrast, the results obtained from using the flashing houselight indicated that such a nonlocalized stimulus can become an effective cue and that frequency of interruption is an effective continuum for studying generalization. In the absence of an appropriate control group, one cannot rule out the possibility that the rapid acquisition obtained with the second stimulus was due to positive transfer from earlier conditions, but it seems unlikely that this was a major factor.

In addition to the merit in generalization testing of using nonlocalized stimuli, frequency of houselight interruption offers the further advantage of technical simplicity and of allowing a straightforward means for regulating response output, namely, by adjusting the amplitude. This manipulation does not appear to change the form of the gradient and is of potential importance for dimensional testing after errorless training (Terrace, 1966), where the problem of a reduced output is a crucial one (Hearst et al, 1970).

Interpretation of inverted gradients along this dimension requires further work on the orthogonality of the dimension with respect to a steady houselight. Until evidence of this kind is obtained, it is not possible to decide whether the functions in Figs. 2 and 3 represent inhibitory gradients or to decide on the cause of the bias towards less responding at high frequencies that was obtained here.

\section{REFERENCES}

GARDNER, R. A \& ELY D. J. A source of artifact in in-line readout projectors.
Journal of the Experimental Analysis of Behavior, 1969, 12,564.

HEARST, E., BESLEY, S., \& FARTHING, G. W. Inhibition and the stimulus control of operant behavior. Journal of the Experimental Analysis of Behavior, 1970. 14, 373-409.

HONIG W. K. BONEAU, C. A., BURSTEIN, K. R., \& PENNYPACKER, H. S. Positive and negative generalization gradients obtained after equivalent training conditions. Journal of Comparative \& Physiological Psychology, $1963,56,111 \cdot 116$

JENKINS, H. M., \& HARRISON, R. H. Generalization gradients of inhibition following auditory discrimination learning. Journal of the Experimental Analysis of Behavior, 1962, 5, 435-441.

SCHWARTZBAUM, J. S., \& KELLICUT, M. $H$. Inverted generalization gradients about a non-reinforced stimulus. Psychological Reports, 1962, 11, 791-792.

TERRACE, H. S. Stimulus control. In W, K. Honig (Ed.), Operant behavior: A reas of research and application. New York: Appleton-Century-Crofts, 1966. 